\title{
Predictors of length of stay in day hospital patients
}

\author{
Sukhwinder S. Shergill, Irshaad Ebrahim and Maurice Greenberg
}

This prospective study assessed the importance of baselline clinical, socio-demographic and diagnostic variables on patient outcome at $\mathrm{six}$ weoks, and their relationship to total length of stay. If included all patients admitted to an acute day hosplital in inner London over a one-year period, and used standardised rating scales. All scales improved after six weeks, but only improvement on the Global Assessment Scale (GAS) predicted the length of stay in those patients who were depressed. There was an increased length of stay in patients with a diagnosis of personality disorder and those admitted with a lower score on the GAS.

Day hospitals play an important role in community care. They have the advantage of offering structured treatment while patients continue to live at home, and thereby maintain patients' links within the community and reduce institutionalisation. The Jules Thorn Day Hospital is an acute psychiatric day hospital with an inner-city catchment area. It offers a mixture of group therapies as well as individual support and medication. The multi-disciplinary team consists of nurses, occupational therapists, a psychologist, a psychiatric social worker, a consultant psychiatrist and a junior psychiatrist (senior house officer with 1 year's psychiatric experience). There is a keyworker system whereby each patient is allocated a named therapist who may be any member of the team except the consultant.

In spite of psychiatric day hospitals being an important resource little is known about which patients benefit most from day patient care (Creed et al, 1988). Vidalis \& Baker (1986) found that basic demographic data failed to predict day hospital responders. Other studies have suggested that diagnosis of personality disorder, among other factors, predicted a poor outcome (Carney et al, 1970).

This study was designed to assess the change in clinical measures in the six weeks following admission, providing an indicator of short-term progress, and the relationship between these and other variables, including diagnosis and sociodemographic factors, to the length of stay. The intention was to provide guidance about those characteristics of patients more suitable for day hospital treatment.

Four scales were chosen for their breadth of outcome and ease of use. (The scales added only 5-10 minutes to standard history and mental state examination.) The two observer-rated scales were the Brief Psychiatric Rating Scale (BPRS) designed to measure patient change over 16 areas of psychopathology on a 7-point scale (Overall \& Gorham, 1962); and the Global Assessment Scale (GAS), a short assessment of global function which is sensitive to change and is rated 0-100 (Endicott et al, 1976). The two patient-rated scales used were Beck's Depression Inventory (BDI) which measures depth of depression over 13 areas on a four-point scale (Beck et al, 1961); and the Social Function Questionnaire (SFQ) which measures social function over eight areas on a four-point scale (Tyrer et al, 1990).

\section{The study}

Over a one-year period (1 September 1993 to 1 September 1994) all admissions to the Jules Thorn Day Hospital were asked for written consent to enter the study. During their first week of admission basic demographic details were collected and patients were assessed on the four outcome scales, in addition to their routine work-up by the day hospital psychiatrist. The scales were repeated at six weeks, or on discharge if earlier, and length of stay at the day hospital was noted at discharge.

All assessments were undertaken by the junior psychiatrists (S.S. and I.E.). Outcome at six weeks was measured from the difference between each scale at the first and sixth week of admission and both initial scores and differences at six weeks were compared to the length of total stay. Since these results were not normally distributed, ranking statistics were used. To address floor and ceiling effects correlation tests were repeated with Pearson's coefficients. Sociodemographic variables, outcome and length of stay were examined with the $K$-sample median test. In the absence of two naturally defined groups, the patients were divided into a shorter 
and longer stay group (more or less than 180 days) and examined using independent $t$-tests for baseline scale ratings and age, and chisquared tests for other baseline socio-demographic variables.

\section{Findings}

\section{Initial measures}

Of 57 admissions over the study period 50 patients completed the study. One was unable to complete the reassessment due to imprisonment, one moved abroad, two refused to cooperate with the study, and three were admitted as in-patients: diagnoses were depression (2), psychotic episode (1), schizophrenia (2) and schizoaffective disorder (2).

The mean age of the sample was 37.3 years (standard deviation (s.d.) 10.7, range 17-61), 27 (54\%) were female, and $25(50 \%)$ lived alone. Patients were referred from the hospital in 33 (66\%) cases and from the community in 17 (33\%). Diagnoses at admission were: schizophrenia $18(36 \%)$, depression $15(30 \%)$, bipolaraffective disorder $18(16 \%)$, personality disorder $8(16 \%)$, and other $1(2 \%)$.

\section{Change at six weeks}

The changes in rating scales between the first and sixth weeks are shown in Table 1. Patients improved on every measure and the changes were compared using the Wilcoxon matchedpairs signed-ranks test (Table 1). The changes in different rating scales are shown correlated against each other in Table 2. There was only one significant correlation of short-term outcome with social factors: patients living alone improved in GAS $(P<0.05)$ when compared to those living with others.

\section{Length of stay}

Demographics and diagnosis One patient had an unclear date of discharge and was omitted from calculations. The mean length of stay was 157.5 days (s.d. 95, median 133 and range 24 $510)$. Thirteen $(27 \%)$ patients had a length of stay longer than six months and 21 (43\%) less than three months. The length of stay across diagnostic groups did not differ significantly. although the length of stay was longer with a diagnosis of personality disorder. The length of stay by diagnosis, with respective mean values and confidence intervals, is shown in Table 3. None of the baseline socio-demographic variables were related to the length of stay $(P<0.10)$.

Rating scales There was no general relationship between baseline scores or change at six weeks and length of stay $(P<0.10)$. However, in patients with a diagnosis of depression, the improvement on the GAS was related to length of stay $(P<0.02)$.

Patients with stay longer than six months When baseline rating scales and age were examined to compare the groups, the only significant findings were that longer stay patients (greater than six months) were significantly younger, mean age 33 years compared to mean age 39 years $(P<0.03)$, and had lower scores on the GAS at admission. mean score $50 v$ v. $44(P<0.03)$. A disproportionate number of patients with personality disorder (5/ 8) were represented in the long-stay group compared to patients with other diagnoses, 2/ 17 schizophrenia, $2 / 8$ bipolar and 4/15 depression $(P<0.15)$. The long-stay group did not differ in living alone, referral source or gender.

\section{Comment}

All rating scales demonstrated improvement at six weeks, and this was most marked with the GAS. Changes in the BPRS correlated with those

Table 1. Change in rating scales

\begin{tabular}{|c|c|c|c|c|c|c|}
\hline Scales & Week & Median & $\begin{array}{l}\text { Interquartile } \\
\text { range }\end{array}$ & $\begin{array}{l}\text { Mean change } \\
\text { weok i-6 }\end{array}$ & $\begin{array}{l}Z \text { score } \\
\text { (significance) }\end{array}$ & $\begin{array}{l}\text { Number } \\
\text { improved } \\
(n=50)\end{array}$ \\
\hline BDI & $\begin{array}{l}1 \\
6\end{array}$ & $\begin{array}{l}16 \\
11\end{array}$ & $\begin{array}{r}10-22 \\
6-17\end{array}$ & -4 & $Z=3.4(P<0.001)$ & 36 \\
\hline BPRS & $\begin{array}{l}1 \\
6\end{array}$ & $\begin{array}{l}21 \\
12\end{array}$ & $\begin{array}{r}14-29 \\
6-16\end{array}$ & -10 & $Z=5.3(P<0.00005)$ & 47 \\
\hline GAS & $\begin{array}{l}1 \\
6\end{array}$ & $\begin{array}{l}49 \\
65\end{array}$ & $\begin{array}{l}45-55 \\
55-70\end{array}$ & +16 & $Z=5.9(P<0.0005)$ & 45 \\
\hline SFQ & $\begin{array}{l}1 \\
6\end{array}$ & $\begin{array}{l}13 \\
12\end{array}$ & $\begin{array}{r}10-16 \\
9-15\end{array}$ & -1 & $Z=2.5(P<0.02)$ & 27 \\
\hline
\end{tabular}

BDI, Beck Depression Inventory; BPRS, Brief Psychiatric Rating Scale; GAS, Global Assessment Scale: SFQ. Social Function Questionnaire. 
Table 2. Correlation between scales

\begin{tabular}{lllll}
\hline SCOlo & BDI & SFQ & GAS & BPRS \\
\hline BDI & 1.00 & & & \\
SFQ & $0.37^{*}$ & 1.00 & & \\
GAS & 0.20 & 0.09 & 1.00 & \\
BPRS & $0.39^{*}$ & 0.10 & $0.38^{*}$ & 1.00 \\
\hline
\end{tabular}

${ }^{*} P<0.01$.

BDI, Beck Depression Inventory; SFQ, Social Function Questionnaire; GAS, Global Assessment Scale; BPRS, Brief Psychiatric Rating Scale.

in BDI and GAS, and those in the BDI correlated with the SFQ. This tends to discount a systematic bias in the use of self-rated against observerrated scales. It is likely that the sensitivity of the GAS may lie in its global assessment, compared to the other scales which measure more specific phenomena.

We collected the same basic demographic data as Vidalis \& Baker (1986) and similarly found that these factors did not predict overall improvement. However, in our study patients living alone improved significantly on the GAS at six weeks compared to those living with others. This improved sociability associated with day hospital admission was noted previously by Michaux et al (1973) and may be attributable to the social facilitation of group therapy. However, contrary to their findings, there was no difference in the SFQ, or length of stay, between patients with a diagnosis of schizophrenia and others. With a relatively small sample size and the use of a ranking correlation test there is the possibility of missing significant correlations (type II errors). This might also be explained by the changes in treatment for schizophrenia over the last 20 years.

Since most patients improve over a six-week period it might be expected that this would be reflected in a shorter admission. However, this was only predicted in depressed patients by the GAS. Possible explanations include the following: patients are kept in the day hospital longer than necessary; factors other than those measured by these scales contribute to the length of stay e.g. perceived need for ongoing support; and the scales do not adequately reflect the difficulties with which patients were initially referred to the day hospital.
A diagnosis of personality disorder was related to increased length of stay. This is consistent with other reports (Carney et al, 1970) and not surprising given the needs of this group of patients. The length of stay is much longer than the eight weeks average quoted by Wilder et al (1966), which may be because they were more severely ill on admission. It is difficult to find psychiatric in-patient beds in London, and the increased bed occupancy levels (Powell et al, 1995) has had an effect on day hospital admissions. The day hospital also concentrates on optimising function in the community, an approach which requires more time. The finding that lower scores on the GAS at admission were related to longer stay suggest that this scale is the best, of the scales used, to look at global functioning of the patient in the community. The finding that younger patients were likely to stay longer may arise because the age of patients having a diagnosis of personality disorder was much lower than the other diagnostic groups.

This study has the limitation of having relatively small numbers which may lack power to find a difference that may exist and limits the possible analyses when wishing to separate into smaller groups for example by diagnoses. The study would have been improved by more frequent follow up with the rating scales, more especially on discharge. More baseline historical data would also have proved useful, especially with regard to previous admissions and length of previous in-patient stays, which were found to be the best predictors in a Manchester day hospital (McGrath \& Tantam, 1987). A measure of change of social circumstances may have allowed a focus on patients having extended stays while awaiting changes in undesirable social conditions. Measures of frequency of attendance may have shown patterns of improvement and attendance in different diagnostic groups.

We were seeking to identify those patients who would gain most from a brief day hospital admission, in order to increase the effectiveness of this resource. In line with previous work with in-patients (Cyr et al, 1983; Baker \& Rochon, 1989; Brock \& Brown, 1993) and in day-patients (McGrath \& Tantam, 1987), there are no clear clinical or demographic predictors of length of stay. Despite most patients showing changes after six weeks, only those with depression who

Table 3. Length of stay (days) by diagnosis

\begin{tabular}{lclccl}
\hline Diagnoats & $\boldsymbol{n}$ & Mean & s.d. & 95\% conididence iniervals & Ronge \\
\hline Schizophrenia & 17 & 136 & 36 & $118-155$ & $94-217$ \\
Bipolar disorder & 8 & 116 & 73 & $54-177$ & $24-217$ \\
Depression & 15 & 162 & 110 & $101-223$ & $44-439$ \\
Neurosis & 1 & 162 & - & - & - \\
Personallity disorder & 8 & 232 & 142 & $113-351$ & $83-510$ \\
\hline
\end{tabular}


improved on the GAS were likely to have a shorter stay. Patients with a low admission rating on the GAS and those with a diagnosis of personality disorder remained longer. The clinical impression was that the longer stay resulted in further improvement. However, in order to demonstrate this conclusively it would be necessary to repeat this study and include an assessment at discharge. Whether there are alternative, more appropriate placements for these longer staying patients, is a question that will still need to be addressed.

\section{Acknowledgement}

We acknowledge the staff of the Jules Thorn Day Hospital for their kind assistance in completing this study.

\section{References}

BAKER, B. \& ROCHON, J. (1989) Length of stay, short stay units and psychlatric emergency admissions. Canadian Journal of Psychiatry, 34, 39-42.

BROCK, I. P. \& BROWN, G. R. (1993) Psychiatric length of stay determinants in a military medical centre. General Hospital Psychiatry, 16. 392-398.

Beck, A. T., WARD, C. H., Mendelson, M.. et al (1961) An inventory for measuring depression. Archives of General Psychiatry, 4, 561-571.

Carney, M. W., Ferguson, R. S. \& Sheffield, B. F. (1970) Psychiatric day hospital and community. Lancet. $i$ 1218-1220.

Creed, F.. Antony, P., Godbert, K., et al (1988) Treatment of severe mental illness in a day hospital. British Joumal of Psychiatry. 164, 341-347.
CYR, J. J. \& HAYLEY, G. A. (1983) Use of demographic and clinical characteristics in predicting length of psychiatric hospital stay: a final evaluation. Journal of Consultant Clinical Psychology, 51, 637-640.

ENDicotT, J., SPITZER, R. L., Fueiss, J. L., et al (1976) The Global Assessment Scale. A procedure for measuring overall psychiatric disturbance. Archives of General Psychiatry. 33, 766-771.

MCGRATH. G. \& TANTAM. D. (1987) Long-stay patients in a psychiatric day hospital. A case note review. British Joumal of Psychiatry. 160, 836-840.

MichauX, M. H., Cheist, M. R., Foster, S. A., et al (1973) Post release adjustment of day and full-time psychiatric patients. Archives of General Psychiatry, 29, 647-651. OVERALL, J. E. \& GORHAM, D. R. (1962) The Brief Psychiatric Rating Scale. Psychological Reports, 10, 799-812.

POWELL, R. B., HOLLANDER, D. \& TOBIANSKY, R. (1995) Crisis in admission beds. Brtish Joumal of Psychiatry. 167. 765-769.

Tyrer. P.. Merson, S., Harrison-Read, P., et al (1990) A pilot study of the effects of early intervention on clinical symptoms and social functioning in psychiatric emergencies. Irish Journal of Psychological Medicine. 7. 132-134.

VIDALUS, A. A. \& BAKER, G. H. B. (1986) Factors influencing effectiveness of day hospital treatment. International Journal of Social Psychiatry. 32, 1-6.

WiLDER, J. F., LEVIN, G. \& ZWERUNG. I. (1966) A two year follow-up evaluation of acute psychotic patients treated in a day hospital. American Journal of Psychiatry, 122. 1095-1101.

Sukhwinder, S. Shergill, Senior Registrar, Maudsley Hospital, London; Irshaad Ebrahim, Senior House Officer, Department of Psychological Medicine, University College Hospital, London; and "Maurice Greenberg. Consultant Psychiatrist, Jules Thorn Day Hospital, St Pancras Hospital, London NWI OPE

*Correspondence 